\title{
Vitimização letal e desigualdade no Brasil Evidências em nível municipal
}

\section{Lethal victimization and inequalities in Brazil}

Evidence at a municipal level

\author{
Eduardo Ribeiro* \\ Ignacio Cano**
}

\begin{abstract}
Resumo: O artigo trata da relação da violência letal com a desigualdade, sob dois pontos de vista. O primeiro é a desigualdade do risco de ser vítima de homicídio entre diversos tipos de pessoas. Nesse sentido, o perfil das vítimas preferenciais da violência letal no Brasil, confirmado pelos últimos dados disponíveis, é muito claro: jovens negros de sexo masculino. O segundo ponto de vista é a relação entre desigualdade de renda e taxa de homicídios. Esta relação depende da unidade de análise escolhida. Os dados analisados aqui, utilizando um modelo multivariado para estimar os fatores associados às taxas municipais de homicídio, mostram que é a renda dos mais pobres e não a desigualdade de renda que está diretamente relacionada à incidência da violência letal. Esses resultados, que contradizem os obtidos na literatura quando se comparam países, sublinham a importância da eleição da unidade de análise.
\end{abstract}

Palavras-chave: Vitimização letal. Homicídios. Desigualdade. Brasil.

\begin{abstract}
This paper deals with the relation between lethal violence and inequality under two approaches. The first one is the inequality in the risk of becoming a victim of homicide among various kinds of people. In this sense, the profile of victims of lethal violence in Brazil is very clear: young black males. The second approach concerns the relation between income inequality and homicide rates. This relation depends on the unit of analysis. Data analysed here, using a multivariate model to estimate factors associated to municipal homicide rates, reveal that it is the average income of the poorest sections of the population rather than income inequality that is directly related to lethal violence. These results contradict those obtained in the literature when countries are compared to each other, which underlines the importance of the choice of unit of analysis.
\end{abstract}

Keywords: Lethal Victimization. Homicides. Inequality. Brazil.

\footnotetext{
*Doutor em Ciências Sociais e pós-doutorando (PNPD/Capes) no PPG em Ciências Sociais da Universidade do Estado do Rio de Janeiro (PPCIS/Uerj) no Rio de Janeiro, RJ, Brasil, e pesquisador do Laboratório de Análise da Violência da mesma universidade $<$ eduardoribeirobr@gmail.com>.

**Doutor em Sociologia pela Universidad Complutense de Madrid, Espanha. Professor associado do Instituto de Ciências Sociais e do PPG em Ciências Sociais da Universidade do Estado do Rio de Janeiro (Uerj) no Rio de Janeiro, RJ, Brasil<ignaciocano62@gmail.com>.
} 


\section{Introdução}

Dentro do marco conceitual da equidade e igualdade na sociedade brasileira, este artigo trata especificamente da violência letal, que pode ser entendida como uma das múltiplas dimensões através das quais as desigualdades se expressam - particularmente no contexto brasileiro. $\mathrm{O}$ trabalho tenta responder a duas questões centrais. A primeira é o grau de desigualdade na distribuição social da violência, ou seja, em que medida o risco de ser vítima de violência é diferente para diversos tipos de pessoas. A segunda é em que medida a desigualdade socioeconômica pode estar associada à violência letal, isto é, se a desigualdade na distribuição de renda é ou não um fator criminogênico, potencialmente gerador de homicídios.

A primeira pergunta pode ser respondida de forma categórica, pois a violência letal afeta de forma desproporcional alguns grupos em comparação com outros, como revelam os dados aqui citados.

A segunda pergunta, porém, apresenta desafios metodológicos significativos, pois sua resposta depende, como será mostrado, da unidade de análise elegida. Em seguida, será testada a relação empírica entre violência letal e desigualdade de renda utilizando os municípios brasileiros como unidade de análise.

\section{Como se distribui o risco de homicídios na população}

O risco de violência letal se distribui de forma muito desigual na sociedade, de forma que as vítimas dos homicídios no Brasil tendem a apresentar um perfil muito bem definido. Todos os estudos realizados têm mostrado que as vítimas são preferencialmente do sexo masculino, jovens e negras. ${ }^{1}$ Em 2010, por exemplo, as taxas de homicídio para homens eram onze vezes superiores às taxas femininas. ${ }^{2}$ Essa composição por sexo é bastante estável. De fato, de 1979 a 2013, o percentual de homens vítimas de homicídios oscilou muito pouco: de $89 \%$ a $92,3 \%$.

Em relação à idade, a taxa de homicídio cresce dramaticamente a partir da adolescência, atingindo seu ápice entre jovens de 20 a 24 anos. A partir dessa faixa, o risco declina progressivamente. Se entre as crianças o risco para os dois sexos é equivalente, na adolescência o incremento é muito mais

\footnotetext{
${ }^{1}$ Por exemplo: Minayo e Souza (1993); Vermelho e Mello Jorge (1996); Waiselfisz (1998, 2006, 2012); Kilsztajn et al. (2004); Soares e Borges (2004); Cano e Ribeiro (2007); PRVL (2010); Borges e Cano $(2011,2014)$.

${ }^{2}$ Fonte: Sistema de Informações sobre Mortalidade (SIM/Datasus) e Censo Demográfico do IBGE. Tabulação realizada pelos autores. Ver Anexo 1.
} 
marcado para os homens. O risco relativo entre a taxa de homicídios de homens e mulheres atinge seu ponto mais alto (por volta de quinze vezes) entre os $20 \mathrm{e}$ 24 anos, justamente a idade de maior risco geral, e cai lenta e progressivamente nas idades mais avançadas. Esse padrão por idade também permaneceu estável entre 2000 e 2010.

Gráfico 1. Taxas de homicídio segundo idade da vítima.

Brasil, 2000 e 2010

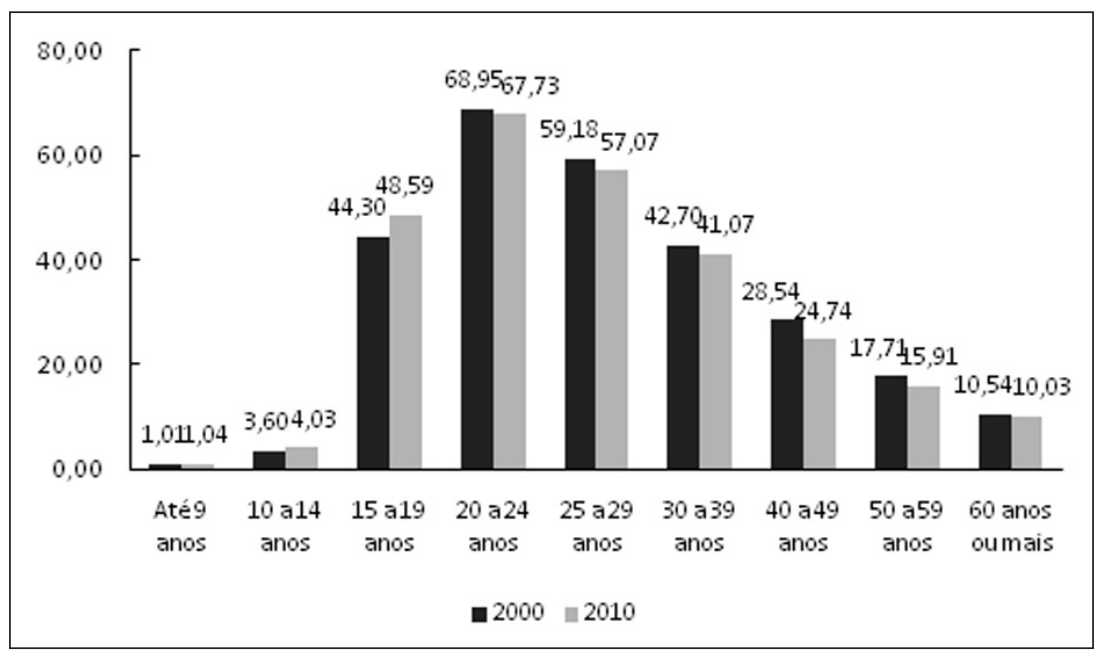

Fonte: Homicídios - SIM/Datasus; População - Censos Demográficos/IBGE.

A população negra no Brasil apresenta taxas de homicídios significativamente superiores às da população branca, embora a estimativa precisa desse diferencial esteja complicada por fatores metodológicos relativos à própria definição da cor. Em 2010, a taxa de homicídios para os brancos era de 17 por 100.000 , enquanto a dos pretos era de 31,5 e a dos pardos de 41. Essa divergência entre as raças reflete também, em alguma medida, um diferencial socioeconômico, visto que os negros apresentam, em geral, status socioeconômico mais desfavorecido.

Quanto à escolaridade, a qualidade do preenchimento dos dados é consideravelmente inferior, mas vários estudos revelam que pessoas de baixa escolaridade sofrem um risco maior (Cano e Ribeiro, 2007). Em suma, o homicídio é um fenômeno que se distribui de forma muito desigual no Brasil e afeta, desproporcionalmente, jovens de sexo masculino, negros e de baixa escolaridade. 


\section{A associação entre violência letal e desigualdade social}

Essa seção tenta responder à pergunta de em que medida a desigualdade social, medida através da desigualdade de renda, pode ser um fator gerador de violência letal. Tradicionalmente, a hipótese mais comum neste campo faz referência à associação entre pobreza, ou baixa renda, e violência letal. Diversas teorias, originárias de matrizes diferentes da criminologia e sociologia da violência, apoiam essa proposta. Assim, nas teorias de matriz econômica, que visualizam o crime como um ato racional (Becker, 1968), acredita-se que quando o ganho esperado nas atividades criminosas, propensas à violência, for maior do que nas atividades dos mercados legais, isso pode estimular a violência. Por sua vez, a pobreza poderia deteriorar a coesão social e gerar anomia (Merton, 1938), que também seriam antecedentes do aumento da violência. A teoria da frustração-agressão (Dollard et al., 1939) poderia ser acionada aqui, na medida em que a pobreza poderia aumentar a frustração e, com ela, a tendência à violência.

Embora a maioria das teorias esteja referida à motivação dos autores da violência (dos agressores), um olhar para as vítimas também oferece explicações plausíveis para a hipótese que vincula pobreza e violência (Cano e Santos, 2001). Em primeiro lugar, pessoas com mais recursos podem "comprar proteção", como segurança privada, blindagens etc. Em segundo lugar, indivíduos com maior renda podem se mudar e abandonar territórios mais perigosos, assumindo que o risco se distribui de forma desigual no espaço, enquanto os mais pobres não teriam essa possibilidade. Em terceiro lugar, numa sociedade tão desigual em termos de acesso a direitos, como a brasileira, na qual a operação do sistema de justiça criminal, sempre sobrecarregado, é também sempre seletiva, é provável que atacar uma pessoa pobre envolva menos risco de captura policial e processamento penal do que vitimizar uma pessoa de classe alta, apesar de esta última poder gerar um butim maior nos crimes contra a propriedade. Isto poderia acabar funcionando como mecanismo protetor para pessoas de maior renda.

Por sua vez, a hipótese da possível conexão entre desigualdade social $e$ violência, que surgiu mais recentemente na literatura, está ancorada em processos teóricos semelhantes, mas nem sempre equivalentes e muitas vezes mais complexos. Para a teoria econômica do criminoso como ator racional (Becker, 1968), o aumento da desigualdade atua nos dois extremos, pois a renda que os pobres obtêm no mercado legal seria menor, aumentando o incentivo para a conduta criminosa, e o butim produto de roubar os mais ricos seria mais elevado. Por outro lado, uma sociedade mais desigual provavelmente 
tenderia a ser menos coesa e mais anômica, o que poderia gerar violência. Da mesma forma, os pobres poderiam sofrer mais frustração em sociedades mais desiguais, ao perceberem o contraste com a riqueza dos ricos, e isso poderia apoiar a teoria da frustração-agressão.

Em relação aos processos que afetam as vítimas, uma maior desigualdade deixaria as pessoas de baixa renda numa posição mais vulnerável, enquanto fortaleceria os indivíduos de alta renda, com um saldo desconhecido em termos do balanço final da violência. Os mais ricos poderiam comprar mais proteção e morar em lugares mais seguros, e os mais pobres estariam na situação contrária. Paralelamente, o custo relativo de atentar contra pessoas de classe alta seria também maior em sociedades menos equitativas.

De qualquer forma, os processos sociais e econômicos que produzem pobreza e desigualdade estão inter-relacionados, de forma que qualquer teste empírico da relação entre desigualdade e violência deve controlar a renda como possível variável interveniente. Por outro lado, o resultado desse teste empírico depende da unidade de análise escolhida e, portanto, começaremos por explicar esse desafio metodológico.

\section{A escolha da unidade de análise}

Nas análises sobre violência letal, tomar a pessoa como unidade de análise permite traçar perfis individuais, destacando fatores de risco ou de proteção. Já o uso de unidades agregadas contabiliza o número de vítimas entre os residentes de determinados territórios, e relaciona o risco de vitimização letal com características desses territórios e de suas populações.

De fato, certos processos podem ser observados para algumas unidades, mas não para outras. Especificamente em relação a unidades de agregação territorial, há muitas evidências de que os resultados das relações entre variáveis podem mudar quando é modificada a unidade de agregação, alterase a escala de observação ou as fronteiras entre áreas (Câmara et al., 2004; Dias et al., 2002). Este efeito é conhecido na literatura como "problema da unidade de área modificável”. No estudo dos homicídios, Cano e Santos (2001) e Soares (2008), entre outros, mostraram como a relação entre violência letal e diversas dimensões estruturais variava de acordo com a unidade de análise.

A escolha da unidade de análise tem também consequências importantes do ponto de vista conceitual, pois define o nível da análise no qual as teorias são postuladas (Della Porta e Keating, 2008). A distinção entre teorias sociológicas (e criminológicas) sobre violência remete ao binômio indivíduo-sociedade. A maioria das teorias que busca explicar crime e violência enfatiza o papel do indivíduo, buscando compreender mediações entre motivações pessoais e 
comportamentos criminosos - recentemente, também das vítimas. Tais teorias estão preocupadas em elucidar a razão pela qual algumas pessoas cometem crimes e outras não. Por sua vez, há também teorias cujo foco é contextual ou grupal, procurando entender os ambientes que levam indivíduos a cometer crimes. Tenta-se responder por que os crimes ocorrem em determinados lugares e não em outros (Cerqueira e Lobão, 2003).

Entretanto, não é raro encontrar defasagem entre as teorias e os dados disponíveis para testá-las. Cano e Santos (2001) assinalaram que, embora a maior parte das teorias do crime se baseie em motivações individuais, os dados para submetê-las a testes empíricos nem sempre estão disponíveis nessa unidade de análise.

No nível individual, a análise está limitada pelo pequeno número de variáveis disponíveis nos documentos relativos às vítimas que são usados como fonte (declarações de óbito ou registros de ocorrência criminal). Em geral, apenas atributos sociodemográficos básicos podem ser empregados e a qualidade do preenchimento nem sempre é boa. Além disso, como os registros não identificam as vítimas, não existe a possibilidade de conjugar informações de diferentes fontes. Por outro lado, esse tipo de registros traz poucas informações sobre criminosos, cujas motivações são protagonistas da maioria das teorias.

Pesquisas sobre os determinantes da violência geralmente utilizam estatísticas agregadas para unidades territoriais, como estados ou municípios, gerando taxas a partir delas. Consequentemente, as teorias costumam ser testadas apenas de forma indireta, com taxas agregadas de vitimização sendo utilizadas para explicar comportamentos individuais dos agressores.

Explicar dinâmicas que operam sobre pessoas a partir de dados espaciais agregados pode provocar distorções como a "falácia ecológica". O fato de áreas habitadas preferencialmente por indivíduos com determinado perfil registrarem vitimização superior não significa, necessariamente, que sejam os indivíduos com esse perfil os que sofrem ou cometem violência. De fato, a concentração de certos grupos em um território é frequentemente um indicador de condições ambientais que afetam toda a população residente.

Por outro lado, considerar dados agregados sobre vítimas para operacionalizar teorias sobre indivíduos agressores assume o pressuposto implícito de que criminosos e vítimas residem nas mesmas áreas e compartilham o mesmo perfil. Esse pressuposto é mais plausível quando as agregações são de grande tamanho (países etc.), e menos verossímil para unidades menores. Isso resulta numa nova contradição. Por um lado, como as 
teorias se referem a indivíduos e os dados a unidades agregadas, quanto menor o tamanho dos territórios utilizado, maior seria a proximidade entre dados empíricos e teoria, e maior seria a possibilidade de que esses dados agregados representassem um coletivo relativamente homogêneo. Por exemplo, dados sobre o nível de pobreza em setores censitários seriam mais representativos das condições de vida de seus moradores do que dados relativos a bairros ou municípios. Por outro lado, como acabamos de ver, quanto menor o tamanho do território, menor a plausibilidade de que vítimas e agressores residam na mesma unidade.

Além dessas considerações gerais relativas ao estudo de dimensões estruturais que se manifestam espacialmente, a tentativa de relacionar desigualdade social e violência apresenta desafios próprios. Mecanismos teóricos que vinculam a motivação para cometer um ato de agressão e o conjunto de fenômenos agrupados na noção de desigualdade social assumem, a princípio, que indivíduos (potenciais agressores) estão percebendo tal desigualdade e agem a partir dessa percepção. Nesse contexto, a questão central é qual seria a escala de percepção da desigualdade (bairro, cidade etc.) que teria mais influência no comportamento individual, a ponto de servir como motivação para uma agressão. Cano e Santos (2001), por exemplo, apontaram que a desigualdade percebida dentro de áreas metropolitanas poderia ter mais impacto do que a desigualdade dentro de bairros ou municípios, considerando que a mobilidade facilitada pela configuração urbana dessas regiões poderia favorecer uma experiência direta com a desigualdade intermunicipal. Assim, os autores sugeriram a necessidade de redesenhar limites geográficos para calcular índices de desigualdade. Outros autores, como Weisburd, Bernasco e Bruinsma (2009), também fizeram reflexões na mesma direção.

\section{Relação entre violência letal, desigualdade social e outras dimensões estruturais mensurada no nível municipal}

O objetivo dessa seção é identificar características municipais associadas ao risco de violência letal em centros urbanos brasileiros, através de um modelo de regressão linear. As variáveis independentes contemplaram um conjunto amplo de indicadores de várias áreas, incluindo desigualdade de renda. A variável dependente é a taxa padronizada de homicídios para o município, calculada a partir dos registros do Sistema de Informações sobre Mortalidade (SIM), do Ministério da Saúde. A análise considerou os 283 municípios brasileiros que possuíam mais de 100.000 habitantes em 2010, o ano do último censo do IBGE. O corte populacional descartou municípios 
com pouca população, que apresentam taxas instáveis e sujeitas a flutuações

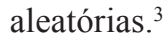

Nas bases do SIM, os homicídios são definidos basicamente como "mortes por agressão" (categorias X85 a Y09 da CID-10). ${ }^{4}$ Foram também consideradas mortes por "intervenção legal" (Y35 e Y36), que são óbitos provocados pela ação da polícia; e ainda uma parcela das "mortes com intenção não determinada" (Y10 a Y34), que configuram uma categoria residual das causas externas, na qual se desconhece se os óbitos foram acidentais ou intencionais. A correção utilizada aqui se baseia na proposta de Cano e Santos (2001). ${ }^{5}$

Para reduzir a influência da composição demográfica dos municípios nas taxas optou-se por estimar taxas padronizadas. O método utilizado foi a padronização direta simultânea, ${ }^{6}$ tomando como base idade e sexo. Após a padronização, a variável dependente sofreu uma transformação logarítmica, visando linearizar sua relação com muitas das variáveis explicativas. Dada essa transformação, os coeficientes da regressão linear podem ser interpretados como o percentual de variação na variável dependente decorrente do acréscimo de uma unidade na variável independente. A partir daqui, quando fizermos menção à "taxa de homicídios", estaremos nos referindo a essa taxa de homicídios padronizada e logaritmizada.

Na identificação das dimensões explicativas foram incorporadas variáveis comumente apontadas pela literatura, agrupadas nas seguintes categorias:

a) Características demográficas: estrutura, dinâmica e composição;

b) Estrutura socioeconômica: renda, pobreza, desigualdade de renda;

\footnotetext{
${ }^{3}$ A instabilidade das taxas é um problema metodológico tradicional nas análises das taxas de homicídio. Como apontou Ribeiro (2008), os homicídios são um evento raro. Isto resulta na instabilidade das taxas no tempo e espaço. A situação se agrava quando taxas são calculadas para áreas pequenas, com populações reduzidas, inferiores a 100.000 habitantes. As alternativas para lidar com o problema incluem usar médias de vários anos, agregar unidades territoriais, selecionar unidades maiores ou reestimar as taxas das áreas mais instáveis com base nas áreas em seu entorno.

${ }^{4}$ As causas básicas de mortalidade são codificadas segundo sua natureza, etiologia e, no caso das mortes por causas externas, segundo o meio ou agente que provocou a lesão letal. A codificação é realizada segundo a Classificação internacional de doenças e problemas relacionados à saúde da OMS, que está em sua $10^{\mathrm{a}}$ revisão, conhecida como CID-10.

${ }^{5}$ Foram consideradas intencionais todas as mortes com intencionalidade não determinada cometidas com armas de fogo ou instrumentos perfuro-cortantes. Posteriormente, estas mortes reclassificadas foram proporcionalmente distribuídas entre homicídios e suicídios, conforme a relação entre estas duas causas existente nos casos com intenção conhecida. Foram também considerados homicídios um total de $10 \%$ dos óbitos com intencionalidade não determinada cometidos com o uso de outros meios, ou seja, meios diferentes de armas brancas ou de fogo.

${ }^{6}$ Mais informações sobre o método podem ser encontradas em Carvalho, Sawyer e Rodrigues (1994).
} 
c) Mercado de trabalho: atividade, desocupação, informalidade;

d) Educação: nível educacional, atendimento à escola, fluxos discentes;

e) Serviços urbanos, condições de vida e de moradia;

f) Vulnerabilidade familiar e estilos de vida;

g) Políticas públicas e despesas orçamentárias municipais.

Diferentes fontes de dados foram exploradas para localizar indicadores municipais para cada uma das categorias. ${ }^{7}$ Em seguida, foi realizada uma primeira seleção de indicadores com base na relação bivariada entre cada variável e a taxa de homicídios. Se o coeficiente de correlação linear de Pearson era significativo, o indicador era incorporado no modelo multivariado inicial.

Um dos desafios na escolha das variáveis se refere à temporalidade para o efeito esperado sobre a violência letal. Como apontado em estudos anteriores (PRVL, 2010; Hartung, 2009), a escolha dessa referência temporal deve refletir um tempo de maturação teoricamente necessário para que determinados processos produzam impacto pleno sobre as dinâmicas geradoras de violência. Em alguns casos, os efeitos esperados podem demorar anos ou décadas, particularmente no relativo aos efeitos que as condições de vida das crianças podem ter no seu comportamento quando atingirem a adolescência e a juventude, faixas em que o risco de homicídio atinge o ponto mais alto. De fato, testes empíricos da correlação com as taxas de homicídio revelaram que, em vários casos, os efeitos mais fortes apareciam quando as variáveis independentes eram defasadas em dez ou até vinte anos.

A modelagem foi realizada por blocos de variáveis, de acordo com as categorias anteriormente mencionadas, começando pelas variáveis demográficas e estruturais, e acabando por variáveis institucionais, culturais e de estilo de vida. Conforme caberia esperar, muitas das variáveis significativas nos modelos iniciais acabavam se tornando não significativas nos modelos posteriores. A decisão sobre significância estatística considerou nível de significância de $5 \%(\alpha=0,05)$.

No início da modelagem foram abordados os fatores demográficos. Os municípios de maior população (representados pelo logaritmo da população em 2010) apresentaram maior risco de vitimização. Por sua vez, a proporção de população urbana no ano 2010 não foi significativa, enquanto os municípios mais urbanizados em 1991 apresentaram, vinte anos depois, menores taxas de vitimização. Isto pode corresponder ao crescimento recente da violência letal nos municípios de porte intermediário (a chamada "interiorização da violência”), processo já relatado por Cruz (1996) e Waiselfisz (2013).

\footnotetext{
${ }^{7}$ Uma descrição das fontes de dados consta no Anexo 1.
} 
Quanto às dinâmicas demográficas, foram consideradas taxas de fecundidade (1991, 2000 e 2010), de crescimento médio anual da população (1991-2000 e 2000-2010); e os percentuais de população migrante em 2000 e 2010 - pessoas que residiam nos municípios há menos de dez anos. Destas variáveis, mostraram-se mais relevantes o crescimento na década de 1991 a 2000 e a migração no ano 2000. Ambos os indicadores com sinal positivo, indicando associação entre crescimento demográfico e processos migratórios, por um lado, e violência por outro.

No entanto, os modelos sugeriram altas correlações entre crescimento demográfico (1991-2000), migração em 2000 e taxa de urbanização de 1991. Para evitar problemas de multicolinearidade ${ }^{8}$ foi criado um indicador único de dinâmica demográfica, através de uma análise fatorial que conjugou crescimento demográfico (1991-2000) e proporção de migrantes em 2000. ${ }^{9}$ Essa variável revelou que municípios com maior dinâmica populacional na década anterior, com maior crescimento e taxas mais elevadas de migração, apresentam maiores taxas de homicídio. A inclusão desta variável fez com que a taxa de urbanização em 1991 perdesse significância estatística.

Por outro lado, considerou-se a proporção de grupos específicos com alto risco de sofrer violência letal. Como duas das principais características do perfil para risco de homicídio (sexo e idade) foram controladas com a padronização das taxas, a única variável testada foi a composição racial. O percentual de população negra em 2010 foi significativo, com correlação positiva com as taxas de homicídio. ${ }^{10}$

Assim, o modelo ajustado com as variáveis demográficas foi composto pelo tamanho da população (logaritmo da população em 2010), percentual de população negra em 2010 e o indicador de dinâmica demográfica entre 1991 e 2000, todas elas com associação positiva com as taxas de homicídio. Este modelo demográfico explicou $34 \%$ da variação total das taxas municipais $\left(\mathrm{R}^{2}\right.$ ajustado $\left.=0,34\right) \cdot{ }^{11}$

\footnotetext{
${ }^{8}$ A multicolinearidade, que acontece quando várias das variáveis independentes apresentam altas correlações entre si, pode provocar grande instabilidade nos coeficientes.

${ }^{9}$ Foi utilizado o primeiro fator, que explicou $82 \%$ da variabilidade.

${ }^{10}$ Foram consideradas negras as pessoas pretas, pardas e indígenas, segundo a classificação do IBGE.

${ }^{11}$ A estatística $R^{2}$ calcula a proporção da variância da variável resposta que foi explicada pelo conjunto das variáveis explicativas no modelo. Quanto mais próximo seu valor estiver de 1, o que indicaria $100 \%$ da variância explicada, melhor é o ajuste do modelo. A versão ajustada desta estatística penaliza a inclusão de muitas variáveis no modelo, permitindo ponderar a relação entre os ganhos obtidos em termos de poder explicativo e o número de variáveis independentes introduzidas.
} 
Em segundo lugar, foram incorporadas variáveis relativas à estrutura socioeconômica (renda, pobreza e desigualdade de renda). Os indicadores de renda de 1991 se mostraram sistematicamente mais correlacionados com as taxas de homicídios de 2010 do que os calculados para o ano 2000, que, por sua vez, apresentaram coeficientes mais elevados do que os de 2010. Desse modo, é possível apontar a existência de efeitos de variáveis estruturais sobre a vitimização dez ou até vinte anos depois. Por outro lado, o impacto da renda variou em relação aos diferentes segmentos de distribuição. As correlações das taxas padronizadas de homicídio com a renda per capita foram estimadas separando a população em quintis de renda. ${ }^{12} \mathrm{O}$ resultado mostrou que a correlação era mais alta para a renda per capita do quintil mais pobre, caindo progressivamente nos quintis de renda subsequentes, um resultado similar ao registrado num estudo anterior sobre homicídios na adolescência (PRVL, 2010).

Tabela 1. Correlação entre o logaritmo da taxa de homicídio padronizada e indicadores de renda

\begin{tabular}{lccc}
\hline \multirow{1}{*}{ Indicadores de Renda } & \multicolumn{3}{c}{ Coeficiente de } \\
& $\mathbf{1 9 9 1}$ & $\mathbf{2 0 0 0}$ & $\mathbf{2 0 1 0}$ \\
\cline { 2 - 4 } & $-0,43$ & $-0,41$ & $-0,36$ \\
\hline Renda per capita & $-0,22$ & $-0,38$ & $-0,09$ \\
Renda per capita média dos extremamente pobres & $-0,55$ & $-0,55$ & $-0,50$ \\
Renda per capita média do 1o quinto mais pobre & $-0,53$ & $-0,52$ & $-0,49$ \\
Renda per capita média do 2o quinto mais pobre & $-0,49$ & $-0,48$ & $-0,45$ \\
Renda per capita média do 3o quinto mais pobre & $-0,44$ & $-0,42$ & $-0,38$ \\
Renda per capita média do 4o quinto mais pobre & $-0,36$ & $-0,35$ & $-0,28$ \\
Renda per capita média do quinto mais rico & $-0,34$ & $-0,34$ & $-0,27$ \\
Renda per capita média do décimo mais rico & & & \\
\hline
\end{tabular}

Em suma, a renda dos mais pobres manifesta uma associação mais clara com os homicídios, tal que nos municípios onde os pobres possuem menos renda, a violência letal é maior. Em termos de política pública, o resultado pode ser interpretado no sentido de que programas de transferência de renda direcionados a setores menos favorecidos poderiam ajudar mais na prevenção da violência do que o crescimento econômico para o conjunto da população.

\footnotetext{
${ }^{12} \mathrm{Em}$ outras palavras, utilizamos a renda média da parcela $20 \%$ mais pobre da população; em seguida, a renda média dos seguintes $20 \%$ e assim por diante, até chegar à renda média dos $20 \%$ mais ricos. Essa é a decomposição disponível nos dados já tabulados por município do Atlas de desenvolvimento humano do Pnud.
} 
Por outro lado, é interessante notar que a correlação da violência letal com a renda dos considerados "extremamente pobres" foi claramente menor. Em 2010, o limiar da "extrema pobreza" estava situado numa renda domiciliar per capita igual ou inferior a 70 reais mensais. Talvez isso possa ser interpretado considerando que os extremamente pobres eram uma proporção muito pequena da população, o que poderia reduzir seu impacto na taxa de homicídios global.

Adicionalmente, tanto a renda média dos pobres quanto as taxas tradicionais de pobreza e extrema pobreza, que indicam o percentual de pessoas com renda domiciliar per capita igual ou inferior a, respectivamente, 140 reais e 70 reais mensais (em reais de agosto de 2010), apresentaram correlações bivariadas mais baixas do que a renda per capita no quintil mais pobre.

Em função desses resultados, foi incluída no modelo demográfico a renda domiciliar média do primeiro quintil mais pobre da população em 1991. Tal inclusão aumentou o percentual de variância explicada de $34 \%$ para $43 \%$, e seu efeito individual foi superior ao das variáveis demográficas.

Para medir a desigualdade de renda dentro do município foram utilizados os índices de Gini e L de Theil, bem como as razões entre os $10 \%$ mais ricos e os $40 \%$ mais pobres e entre os $20 \%$ mais ricos e os $40 \%$ mais pobres. Para todos esses índices, independentemente do ano observado, as correlações bivariadas com a taxa de homicídios foram positivas e significativas, indicando que maiores níveis de desigualdade de renda estavam relacionados a maiores taxas de homicídio. Entretanto, a magnitude dos coeficientes foi menor que a observada para os indicadores de renda. Como acontecia com estes últimos, os coeficientes defasados em vinte anos (para 1991) apresentaram maiores correlações.

Tabela 2. Correlação entre log da taxa de homicídio padronizada e indicadores de desigualdade de renda

\begin{tabular}{lccc}
\hline \multirow{2}{*}{\multicolumn{1}{c}{ Indicadores de Desigualdade }} & \multicolumn{3}{c}{ Coeficiente de correlação no ano } \\
\cline { 2 - 4 } & $\mathbf{1 9 9 1}$ & $\mathbf{2 0 0 0}$ & $\mathbf{2 0 1 0}$ \\
\hline Índice de Gini & 0,23 & 0,14 & 0,14 \\
Índice L de Theil & 0,24 & 0,14 & 0,17 \\
Razão 10\% mais ricos / 40\% mais pobres & 0,26 & 0,18 & 0,16 \\
Razão 20\% mais ricos / 40\% mais pobres & 0,27 & 0,18 & 0,16 \\
\hline
\end{tabular}


No modelo multivariado, que já continha a renda do quintil mais pobre, a introdução das variáveis que mensuravam desigualdade de renda não mostrou impacto significativo. Em outras palavras, é a renda dos mais pobres e não a desigualdade dentro do município que apresenta uma relação mais forte com a violência letal. Observe-se que este resultado contrasta com o obtido na literatura utilizando países como unidade de análise, pois neste caso é a desigualdade de renda que revela impacto maior (Fajnzylber et al., 1998). Ou seja, são os países mais desiguais e não os mais pobres os que se revelaram mais violentos.

Foram também testados indicadores de Mercado de trabalho, como taxas de ocupação (desemprego aberto), índices de participação, taxas de informalidade e precarização dos postos de trabalho. No modelo multivariado, com variáveis demográficas e socioeconômicas, a desocupação em 2010, calculada para a população com 10 anos ou mais de idade, foi positiva e estatisticamente significativa. Maiores níveis de desemprego estavam associados a maiores níveis municipais de violência letal. Esta variável se mostrou mais forte do que taxas de desemprego calculadas para populações específicas, como os jovens. Por sua vez, a inclusão da taxa de desocupação fez com que o percentual de negros se tornasse não significativo e saísse do modelo.

A dimensão educacional contemplava indicadores de acesso à escola (taxas de atendimento), nível de escolaridade e rendimento escolar. Os indicadores educacionais estavam altamente correlacionados entre si. Assim, após uma triagem inicial, os seguintes indicadores foram testados no modelo multivariado: a) proporção de crianças fora da escola em 2000; b) taxa de escolarização líquida no Ensino Médio em 2010; c) distorção idade-série em 2010 e; d) taxa de aprovação nos anos finais do Ensino Fundamental em 2010. A taxa de escolarização líquida no Ensino Médio em 2010 obteve os melhores resultados e depois de sua inclusão, outras variáveis educacionais perderam significância. A taxa equivale ao percentual de estudantes adolescentes (15 a 17 anos) frequentando ensino médio regular seriado. O coeficiente negativo significativo permite dizer que municípios com menores níveis de abandono escolar entre adolescentes apresentam maiores taxas de homicídio. O indicador educacional elevou o poder explicativo do modelo de $44 \%$ para $53 \%$. Como outros estudos revelaram, a educação é uma dimensão central na explicação da distribuição da violência letal.

Do ponto de vista das condições do habitat urbano foram testadas variáveis relativas à provisão de serviços como água, esgoto, coleta de lixo, energia elétrica, pavimentação e iluminação, além de outras relativas a condições de 
moradia, como adequação das residências e densidade domiciliar. O percentual de pessoas residentes em domicílios com abastecimento de água e esgotamento sanitário inadequados em 2010 foi a única dessas variáveis estatisticamente significativas, apresentando coeficiente negativo. Uma proporção maior de domicílios com estes serviços inadequados parece estar associada a menores taxas de homicídio. Este resultado, contrário ao esperado, poderia estar sendo afetado pelos diferentes níveis de urbanização dos municípios, considerando que municípios mais urbanos, e mais violentos, tendem a ter melhores serviços urbanos. Até aqui, o modelo multivariado explicava $54,6 \%$ da variabilidade das taxas de homicídio.

A vulnerabilidade familiar incluiu indicadores que mensuravam gravidez precoce (em duas faixas: de 10 a 14 anos e de 15 a 17 anos), o percentual de pessoas de 15 a 24 anos que não estudavam nem trabalhavam e eram vulneráveis à pobreza (em 2000 e 2010), ${ }^{13}$ e o percentual de mulheres responsáveis por domicílios, sem cônjuge e com pelo menos um filho menor do que 15 anos. $O$ percentual de adolescentes (entre 15 e 17 anos) que tiveram filhos, para o ano de 2010, foi a única variável significativa no modelo multivariado, com coeficiente positivo, que expressava maior risco de vitimização nos municípios com maiores níveis de gravidez precoce.

Em relação aos estilos de vida dos indivíduos, foram analisados o estado civil (proporção de solteiros ou pessoas sem união estável), deslocamentos temporários para estudo ou trabalho em outros municípios, e a religião (proporção de católicos, evangélicos e de pessoas sem religião).

Dois indicadores de mobilidade urbana apresentaram coeficientes significativos e positivos - as chamadas taxas de atração e de repulsão. A primeira indica a proporção de pessoas que entram regularmente no município para trabalhar ou estudar, enquanto a segunda reflete o percentual de pessoas que saem regularmente para trabalhar ou estudar em outro município. Em ambos os casos, quanto maior a mobilidade pendular, maiores as taxas de homicídio.

Tais resultados podem ser interpretados pela vinculação da violência letal às regiões metropolitanas (ver Ribeiro, 2008 e PRVL, 2010), na medida em que esse tipo de deslocamento tende a ser mais comum em contextos metropolitanos, conurbados e com maior oferta de transporte intermunicipal.

\footnotetext{
${ }^{13}$ A definição de vulnerável à pobreza, segundo o Atlas de Desenvolvimento Humano do Pnud 2013, diz respeito a moradores com renda domiciliar per capita igual ou inferior a 255 reais mensais, em agosto de 2010, o equivalente a 1/2 salário mínimo.
} 
Por outro lado, a saída dos residentes, mesmo que temporária, pode se refletir em laços comunitários mais frouxos e em menores níveis de controle social informal.

O percentual de pessoas que se declararam evangélicas em 2010 apresentou correlação positiva com a incidência de homicídios, de modo que, quanto maior a proporção de evangélicos na população, mais alta é a violência letal. Este resultado, que já apareceu em estudos anteriores (PRVL, 2010), talvez possa ser interpretado no sentido de que o crescimento dos evangélicos acontece justamente em áreas mais pobres e mais expostas à violência. A proporção de fiéis de outras religiões, bem como o percentual de pessoas sem religião, não foi significativa.

Uma última dimensão remete aos esforços em termos de investimentos e políticas públicas nos municípios. Foram observados gastos públicos em segurança, educação, assistência social, lazer, além do número de guardas municipais por habitante e da proporção de habitantes beneficiários pelo programa Bolsa Família.

Os gastos per capita com educação e cultura foram significativos nas correlações bivariadas, ambas com sinal negativo. Nos modelos de regressão múltipla, entretanto, apenas as despesas com cultura foram significativas. $\mathrm{O}$ sinal negativo do coeficiente aponta que quanto maiores os investimentos em cultura, menores são as taxas municipais de vitimização letal.

Outra variável significativa foi a existência de um conselho municipal de segurança pública. Tais conselhos têm como finalidade dar suporte ao planejamento e acompanhamento das políticas municipais de segurança. $\mathrm{O}$ coeficiente foi positivo, contrário ao esperado, apontando que a existência deste dispositivo institucional está relacionada a taxas de vitimização mais elevadas. Apesar da hipótese inicial na direção contrária, a de que o Conselho poderia reduzir a violência, o resultado pode ser interpretado no sentido de que os conselhos são criados apenas nos municípios onde a segurança pública é uma questão mais grave. ${ }^{14}$ Em outras palavras, esta variável apresenta um claro grau de endogeneidade em relação à violência.

O modelo final (tabela 3), explicou $63,5 \%$ da variação das taxas de homicídio.

\footnotetext{
${ }^{14}$ Cabe lembrar que constitucionalmente a gestão da política de segurança pública não é responsabilidade dos municípios. Apenas na última década começaram a surgir com maior intensidade políticas de segurança municipais.
} 
Tabela 3. Regressão múltipla para explicação do risco de vitimização letal em 2010

\begin{tabular}{|c|c|c|c|c|}
\hline \multirow[b]{2}{*}{ Variáveis no modelo multivariado } & \multicolumn{3}{|c|}{ Coeficientes } & \multirow{2}{*}{$\begin{array}{l}\text { P-valor } \\
\text { (sig) }\end{array}$} \\
\hline & B & $\begin{array}{c}\text { Erro } \\
\text { padrão }\end{array}$ & b & \\
\hline Constante & 1,794 & 0,504 & & 0,000 \\
\hline Logaritmo da População em 2010 & 0,182 & 0,034 & 0,21 & 0,000 \\
\hline $\begin{array}{l}\text { Dinâmica Demográfica na década } \\
\text { 1990-2000 }\end{array}$ & 0,089 & 0,029 & 0,13 & 0,002 \\
\hline $\begin{array}{l}\text { Renda domiciliar per capita média do } \\
\text { quinto mais pobre em } 1991\end{array}$ & $-0,007$ & 0,001 & $-0,41$ & 0,000 \\
\hline $\begin{array}{l}\text { Taxa de frequência líquida ao } \\
\text { Ensino Médio em } 2010\end{array}$ & $-0,025$ & 0,005 & $-0,30$ & 0,000 \\
\hline $\begin{array}{l}\text { Pessoas com abastecimento de água } \\
\text { e esgotamento sanitário inadequados } \\
\text { em } 2010(\%)\end{array}$ & $-0,02$ & 0,005 & $-0,18$ & 0,000 \\
\hline $\begin{array}{l}\text { Mulheres de } 15 \text { a } 17 \text { anos que tiveram } \\
\text { filhos em } 2010(\%)\end{array}$ & 0,091 & 0,016 & 0,29 & 0,000 \\
\hline $\begin{array}{l}\text { Atração em 2010: Pessoas que chegam } \\
\text { para trabalhar ou estudar }(\%)\end{array}$ & 0,024 & 0,005 & 0,22 & 0,000 \\
\hline $\begin{array}{l}\text { Repulsão em 2010: Pessoas que saem } \\
\text { para trabalhar ou estudar (\%) }\end{array}$ & 0,009 & 0,003 & 0,12 & 0,007 \\
\hline População Evangélica em 2010 (\%) & 0,014 & 0,004 & 0,14 & 0,000 \\
\hline $\begin{array}{l}\text { Média da despesa orçamentária } \\
\text { per capta com a função Cultura entre } \\
2008 \text { e } 2010\end{array}$ & $-0,006$ & 0,002 & $-0,11$ & 0,020 \\
\hline $\begin{array}{l}\text { Existência de conselho municipal de } \\
\text { segurança pública em } 2009\end{array}$ & 0,193 & 0,054 & 0,13 & 0,000 \\
\hline
\end{tabular}

Variável dependente: Logaritmo natural da taxa padronizada de homicídios em 2010.

Amostra de municípios com mais de 100.000 habitantes em 2010 (n=283).

Resumindo os resultados, os municípios que apresentaram maior risco de vitimização letal em 2010 eram aqueles que apresentavam, em média:

a) maior população em 2010 ;

b) maior dinâmica populacional entre 1990 e 2000, com maior crescimento populacional e chegada de migrantes;

c) menor renda média na parcela mais pobre da população (o primeiro quintil de renda) em 1991. A defasagem do efeito mostra que o contexto socioeconômico determina as chances de violência vinte anos depois, quando coortes nascidas naquele período chegaram às faixas etárias de maior risco de homicídio; 
d) sistemas de ensino com menor retenção escolar em 2010, ou seja com uma proporção menor de adolescentes matriculados no nível de ensino idealizado para sua idade;

e) menor proporção da população sem saneamento básico aceitável em 2010, ao contrário do que se esperava;

f) maiores taxas de gravidez precoce entre os 15 e 17 anos em 2010;

g) maior mobilidade pendular em 2010, com maiores contingentes populacionais chegando ou saindo do município diariamente, para trabalho ou estudo;

h) maior proporção de evangélicos em 2010, o que pode estar associado ao fato de que os evangélicos têm avançado mais em áreas mais pobres e degradadas;

i) menores despesas médias anuais per capita com a função orçamentária Cultura entre 2008 e 2010;

j) existência de Conselhos municipais de segurança em 2009.

A desigualdade de renda, representada por vários indicadores tradicionais como o índice de Gini, o L de Theil e as razões entre os rendimentos médios dos quintis mais pobres e mais ricos, não foi relevante para explicar os homicídios, uma vez consideradas outras variáveis explicativas. Tais variáveis foram sistematicamente testadas para 1991, ano em que as correlações foram mais elevadas (ver tabela 2), em dois momentos da análise multivariada: durante o processo de construção do modelo estatístico, entrando no bloco com outras variáveis da categoria analítica estrutura socioeconômica, e após a escolha do modelo final (tabela 3). Em ambos os casos os coeficientes não foram significativos.

\section{Considerações finais}

Esse artigo apresentou, em primeiro lugar, a vitimização letal como uma entre tantas outras dimensões através das quais a desigualdade se expressa. Foram expostas as principais disparidades em relação ao risco individual das pessoas de sofrer violência letal, reafirmando o que a literatura sobre o tema denomina como vítimas preferenciais: homens, jovens, negros e pessoas de baixa escolaridade.

Em segundo lugar, foi explorada a associação entre desigualdade de renda e incidência de violência letal, que depende crucialmente da escolha da unidade de análise. Foram apresentadas evidências empíricas dos fatores associados à vitimização em nível municipal. Regressões múltiplas foram ajustadas para explicar as taxas municipais de homicídio em 2010, apenas para municípios com mais de 100.000 habitantes. 
A incidência da violência letal parece fortemente associada a elementos estruturais, demográficos e socioeconômicos. Neste último caso, distribuição de renda e acesso à educação foram características fundamentais para entender o comportamento das taxas. Outras variáveis relativas a estilos de vida e arranjos familiares também foram relevantes, tais como as taxas de mobilidade urbana pendular, a gravidez na adolescência e o percentual de população evangélica.

Dentro das variáveis estruturais, destacou-se a demora (ou defasagem) com que algumas condições imperantes se relacionavam à incidência de violência. A renda média e a desigualdade de renda, por exemplo, tiveram correlações sistematicamente mais elevadas para seus termos defasados em dez ou até vinte anos, indicando que o abandono de certas populações pode gerar efeitos a médio e longo prazo sobre a violência letal, quando a coorte dos nascidos naquele momento atingir o momento vital de maior risco.

Por outro lado, o estudo mostrou que a renda média do quintil mais pobre da população possui maior efeito sobre a vitimização letal, de forma que ele torna o impacto da desigualdade de renda dentro do município não significativo. Em outras palavras, é a pobreza dos residentes mais pobres dos municípios e não a desigualdade de renda dentro desses municípios que parece influenciar a incidência de homicídios. O contraste desse resultado com outros estudos que compararam taxas de países sublinha a transcendência da escolha da unidade de análise.

Do ponto de vista das políticas públicas, os resultados desse estudo parecem favorecer o investimento em programas de transferência de renda e de programas educacionais como os mais adequados para a prevenção da violência letal.

\section{Referências}

BECKER, Gary Stanley. Crime and punishment: an economic approach. Journal of Political Economy, v. 76, n. 2, p. 169-217, 1993.

BORGES, Doriam; CANO, Ignacio (orgs.). Homicídios na adolescência no Brasil: IHA 2008. Rio de Janeiro: Observatório de Favelas, 2011.

BORGES, Doriam; CANO, Ignacio (orgs.). Índice de homicídios na adolescência: IHA 2012. Rio de Janeiro: Observatório de Favelas, 2014.

CÂMARA, Gilberto; MONTEIRO, Antônio Miguel Vieira; DRUCK, Suzana; CARVALHO, Marília Sá. Análise espacial e geoprocessamento. In: Suzana Druck; Marília Sá Carvalho; Gilberto Câmara; Antônio Miguel Vieira Monteiro (orgs.). Análise espacial de dados geográficos. Planaltina: Embrapa, 2004. p. 21-52. 
CANO, Ignacio; RIBEIRO, Eduardo. Homicídios no Rio de Janeiro e no Brasil: dados, políticas públicas e perspectivas. In: Marcus Vinicius G. da Cruz; Eduardo Cerqueira Batitucci (orgs.). Homicídios no Brasil. Rio de Janeiro: FGV, 2007. p. 51-78.

CANO, Ignacio; SANTOS, Nilton. Violência letal, renda e desigualdade social no Brasil. Rio de Janeiro: 7Letras, 2001.

CARVALHO, José Alberto Magno de; SAWYER, Diana Oya; RODRIGUES, Roberto do Nascimento. Introdução a alguns conceitos básicos e medidas em demografia. 2. ed. São Paulo: Abep, 1994.

CERQUEIRA, Daniel; LOBÃO, Waldir. Determinantes da criminalidade: uma resenha dos modelos teóricos e resultados empíricos. Rio de Janeiro: Ipea, 2003 (Texto para discussão, n. 956).

CRUZ, Oswaldo Gonçalves. Homicídios no estado do Rio de Janeiro: análise da distribuição espacial e sua evolução. São Paulo, 1996. Dissertação (Mestrado) - Universidade de São Paulo. Faculdade de Saúde Pública. Departamento de Epidemiologia.

DELLA PORTA, Donatella; MICHAEL Keating (eds.). Approaches and methodologies in the social sciences: a pluralist perspective. Cambridge University Press, 2008.

DIAS, Taciana de Lemos et al. Problemas de escala e a relação área-indivíduo em análise espacial de dados censitários. Informática Pública, v. 4, n. 1, p. 89-104, 2002.

DOLLARD, John; MILLER, Neal E.; DOOB, Leonard W.; MOWRER, O. H.; SEARS, Robert R. Frustration and aggression. New Haven: Yale University Press, 1939.

FAJNZYLBER, P.; LEDERMAN, D.; LOAYZA, N. Determinants of crime rates in Latin America and the world: an empirical assessment. World Bank Latin American and Caribbean Studies. Washington, D. C.: World Bank, 1998 <10.1596/0-8213-4240-1>. HARTUNG, Gabriel Chequer. Ensaios em demografia e criminalidade. Tese (Doutorado) - EPGE, Fundação Getúlio Vargas, Rio de Janeiro, 2009.

KILSZTAJN, Samuel et al. Vítimas da cor: homicídios na região metropolitana de São Paulo, Brasil, 2000. Cadernos de Saúde Pública, v. 21, n. 5, p. 1408-1415, 2005.

MERTON, Robert King. Social structure and anomie. American Sociological Review, v. 3, n. 5, p. 672-682, $1938<10.2307 / 2084686>$.

MINAYO, Maria Cecília de S.; SOUZA, Edinilsa R. de. Violência para todos. Cadernos de Saúde Pública, v. 9, n. 1, p. 65-78, 1993.

PRVL-Programa de redução da violência letal contra jovens e adolescentes. Homicídios na adolescência no Brasil: IHA 2005/2007. Brasília: Secretaria de Direitos Humanos, 2010.

RIBEIRO, Eduardo. Configuração espacial e fatores associados à vitimização por homicídio nos municípios brasileiros. Rio de Janeiro, 2008. Dissertação (Mestrado) Escola Nacional de Ciências Estatísticas, ENCE/IBGE.

SOARES, Gláucio Ary Dillon. Não matarás: desenvolvimento, desigualdade e homicídios. Rio de Janeiro: FGV, 2008. 
SOARES, Gláucio Ary Dillon; BORGES, Doriam Luís de Melo. A cor da morte. Ciência Hoje, v. 35, n. 209, p. 26-31, 2004.

VERMELHO, Letícia Legay; MELLO JORGE, Maria Helena P. de. Mortalidade de jovens: análise do período de 1930 a 1991 (a transição epidemiológica para a violência). Revista de Saúde Pública, v. 30, n. 4, p. 319-331, $1996<10.1590 /$ S003489101996000400005>.

WAISELFISZ, Julio Jacobo. A cor dos homicídios no Brasil. Brasília: Abrufdatum, 2012.

WAISELFISZ, Julio Jacobo. Mapa da violência 2006: os jovens do Brasil. Brasília: UNESCO, Instituto Ayrton Senna, SEDH, 2006.

WAISELFISZ, Júlio Jacobo. Mapa da Violência 2013: homicídios e juventude no Brasil. Rio de Janeiro: Cebela/Flacso, 2013.

WAISELFISZ, Julio Jacobo. Mapa da violência: os jovens do Brasil. Rio de Janeiro: UNESCO, Instituto Ayrton Senna, Garamond, 1998.

WEISBURD, David; BERNASCO, Wim; BRUINSMA, Gerben (orgs.). Putting crime in its place: units of analysis in geographic criminology. Springer Science \& Business Media, 2009.

Autor correspondente:

Eduardo Ribeiro

Laboratório de Análise da Violência (LAV)

Uerj/Pavilhão João Lyra Filho

Rua São Francisco Xavier 524, 9o andar, sala 9103, bloco F - Maracanã

20550-900 Rio de Janeiro, RJ, Brasil

Recebido em: 10 fev. 2016

Aprovado em: 27 abr. 2016 


\section{ANEXO I}

\section{Fontes de dados municipais para os indicadores sociais}

\section{Censo Demográfico - IBGE}

Dados socioeconômicos e demográficos para 1991, 2000 e 2010. Informações coletadas a partir do Sistema IBGE de Recuperação de Dados (Sidra), ${ }^{15}$ usando dados da amostra.

2. Pesquisa de Informações Básicas Municipais (Munic) - IBGE ${ }^{16}$

Levanta dados institucionais junto às prefeituras de todos os municípios brasileiros. Para 2009, foram consultados dados sobre políticas de segurança, existência de órgãos de gestão local da segurança pública, existência e efetivo das guardas municipais.

3. Sistema de Contas Nacionais, Produto Interno Bruto dos Municípios - IBGE ${ }^{17}$ Traz dados sobre o Produto Interno Bruto (PIB) municipal. Os dados estavam disponíveis segundo município e ano, para o intervalo de 1999 a 2013. Foram testados 2000 e 2010.

\section{Atlas do Desenvolvimento Humano no Brasil 2013 - Pnud ${ }^{18}$}

Projeto do Pnud que compila indicadores com base nos últimos três censos do IBGE. Disponibiliza o Índice de Desenvolvimento Humano Municipal (IDHM), e indicadores em dimensões como educação, habitação, saúde, trabalho, renda e vulnerabilidade.

5. Secretaria do Tesouro Nacional - STN/Ministério da Fazenda ${ }^{19}$.

Dados sobre receitas e despesas orçamentárias por função, contas e finanças públicas municipais. Foram utilizados os anos 2008, 2009 e 2010.

6. Ministério do Desenvolvimento Social e Combate à Fome - MDS

Dados sobre o Programa Bolsa Família (PBF) - número de famílias beneficiadas e valor total dos benefícios no município, para 2010. Dados disponíveis no IpeaData. ${ }^{20}$

7. Instituto Nacional de Estudos e Pesquisas Educacionais Anísio Teixeira - Inep ${ }^{21}$ Fornece indicadores educacionais municipais - distorção idade-série, taxa de abandono e reprovação - com base no Censo Escolar da Educação Básica. Dados para 2010.

8. Observatório das Metrópoles ${ }^{22}$

Com dados sobre movimentos pendulares entre municípios e níveis de integração metropolitana, compilados com base no Censo do IBGE. Dados para 2010.

9. Sistema de Informações sobre Mortalidade ${ }^{23}$

O número total de homicídios foi obtido a partir do Sistema de Informações sobre Mortalidade (SIM), do Ministério da Saúde - criado pelo Datasus para obtenção regular de dados sobre mortalidade no país. O SIM disponibiliza microdados, que têm o indivíduo falecido como unidade de análise. O primeiro ano disponível é 1979.

\footnotetext{
${ }^{15}<$ www.sidra.ibge.gov.br>.

${ }^{16}<$ www.ibge.gov.br/home/estatistica/economia/perfilmunic/defaulttab1_perfil.shtm>.

${ }^{17}<$ www.sidra.ibge.gov.br/bda/pesquisas/PIBMun/default.asp $>$.

$18<$ www.atlasbrasil.org.br/2013>.

${ }^{19}<$ www.tesouro.fazenda.gov.br/estados_municipios/>.

${ }^{20}<$ www.ipeadata.gov.br $>$.

${ }^{21}<$ www.portal.inep.gov.br/indicadores-educacionais $>$.

${ }^{22}<$ www.observatoriodasmetropoles.net/index.php? option $=$ com_content\&view $=$ article \& id $=152>$.

${ }^{23}<$ www.datasus.saude.gov.br/informacoes-de-saude/servicos $2 /$ transferencia-de-arquivos $>$.
} 